\title{
Evaluation of Additive Manufacturing for Stainless Steel Components
}
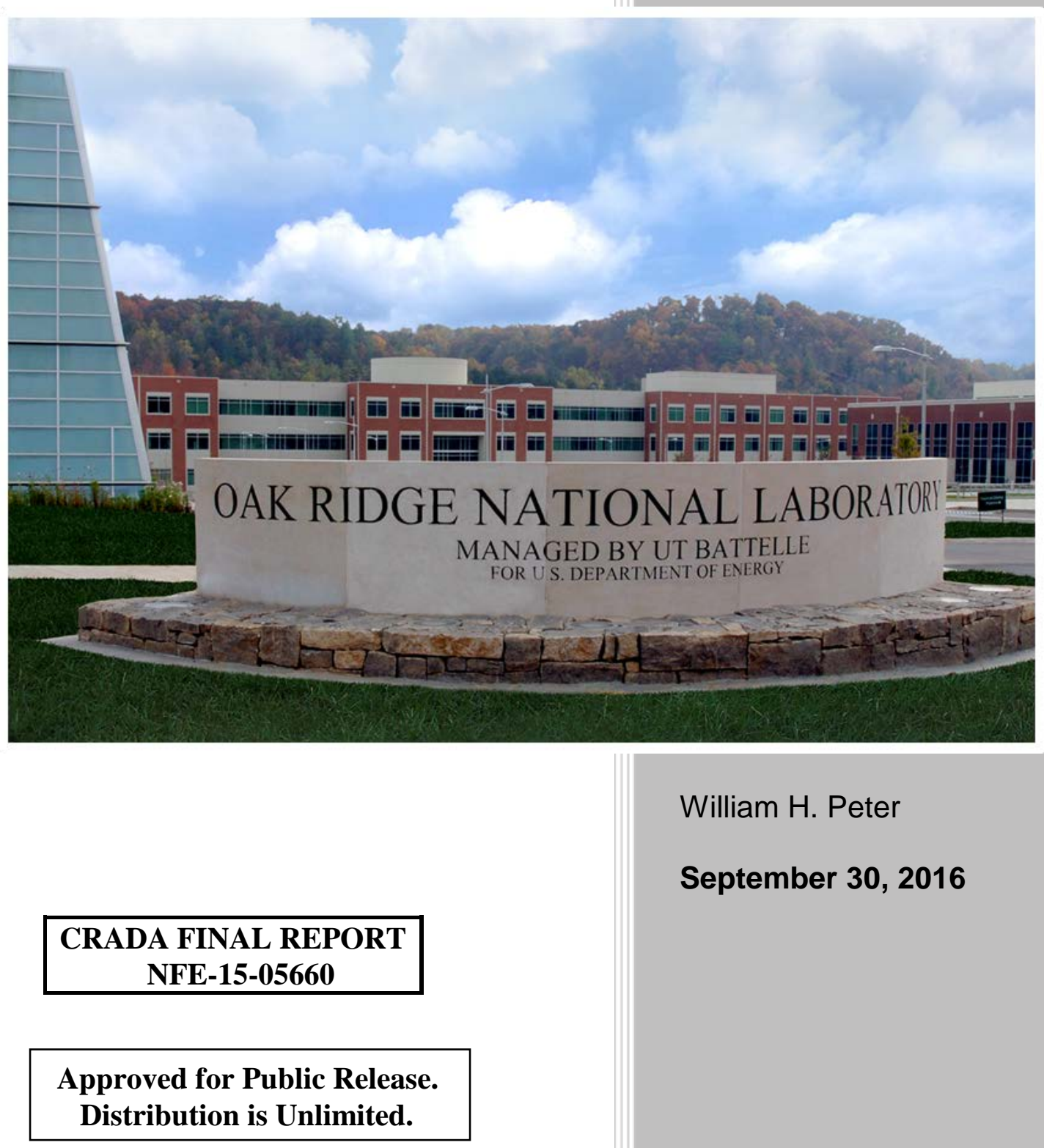

William H. Peter

September 30, 2016 


\section{DOCUMENT AVAILABILITY}

Reports produced after January 1, 1996, are generally available free via US Department of Energy (DOE) SciTech Connect.

Website http://www.osti.gov/scitech/

Reports produced before January 1, 1996, may be purchased by members of the public from the following source:

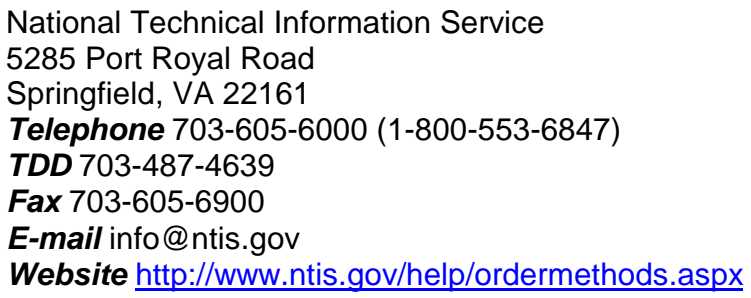

Reports are available to DOE employees, DOE contractors, Energy Technology Data Exchange representatives, and International Nuclear Information System representatives from the following source:

Office of Scientific and Technical Information

PO Box 62

Oak Ridge, TN 37831

Telephone 865-576-8401

Fax 865-576-5728

E-mail reports@osti.gov

Website http://www.osti.gov/contact.html

This report was prepared as an account of work sponsored by an agency of the United States Government. Neither the United States Government nor any agency thereof, nor any of their employees, makes any warranty, express or implied, or assumes any legal liability or responsibility for the accuracy, completeness, or usefulness of any information, apparatus, product, or process disclosed, or represents that its use would not infringe privately owned rights. Reference herein to any specific commercial product, process, or service by trade name, trademark, manufacturer, or otherwise, does not necessarily constitute or imply its endorsement, recommendation, or favoring by the United States Government or any agency thereof. The views and opinions of authors expressed herein do not necessarily state or reflect those of the United States Government or any agency thereof. 
ORNL/TM-2016/541

CRADA/NFE-15-05660

Materials Science \& Engineering Division Advanced Manufacturing Office

\title{
Evaluation of Additive Manufacturing for Stainless Steel Components
}

\author{
Authors \\ William H. Peter, Oak Ridge National Laboratory \\ Xiaoyuan Lou, GE Global Research \\ Frederick A. List, Oak Ridge National Laboratory \\ David Webber, GE-Hitachi Nuclear Energy
}

Date Published:

September 16, 2016

Prepared by

OAK RIDGE NATIONAL LABORATORY

Oak Ridge, Tennessee 37831-6283

managed by

UT-BATTELLE, LLC

for the

US DEPARTMENT OF ENERGY

under contract DE-AC05-00OR22725

Approved For Public Release 



\section{CONTENTS}

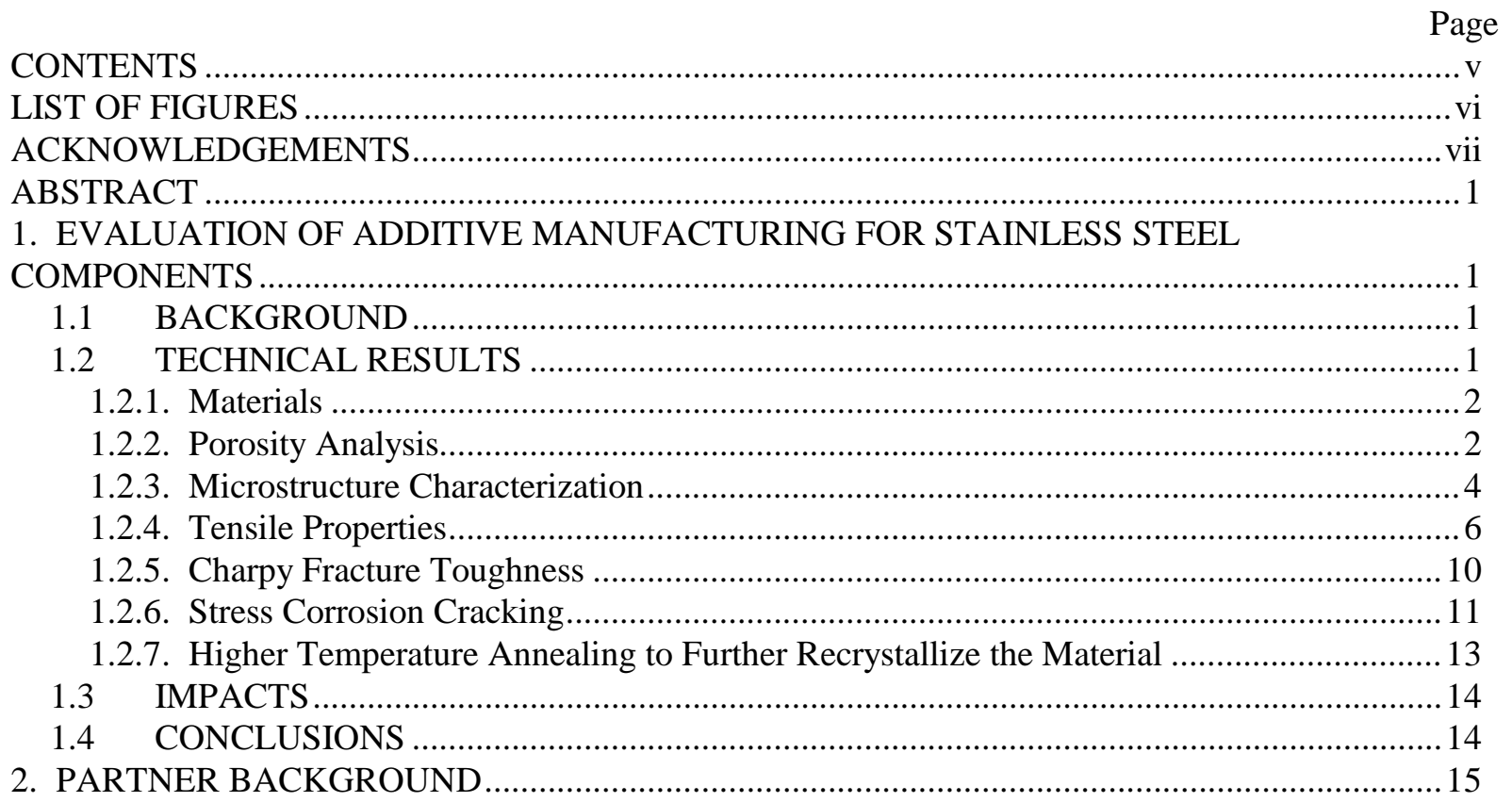




\section{LIST OF FIGURES}

Fig. 1. Test specimens prepared at Oak Ridge National Laboratory and shipped to GE Global Research

for characterization.

Fig. 2. Optical view of both horizontal cross-section and vertical cross-section. 3

Fig. 3. SEM cross-section image of the horizontal oriented specimen. 5

Fig. 4. SEM cross-section image of the vertical oriented specimen. $\quad 6$

Fig. 5. Tensile properties of solution annealed AM316L SS with different orientations at room temperature. $\quad 8$

Fig. 6. Tensile properties of solution annealed AM316L SS with different orientations at $288^{\circ} \mathrm{C} . \quad 10$

Fig. 7. Charpy toughness of solution annealed AM316L SS along different orientation. 11

Fig. 8. The orientation of compact tension specimens in the material. A $20 \%$ warm forge was performed before machining.

Fig. 9. Corrosion fatigue crack growth rate under different load cyclic conditions in high temperature water.

Fig. 10. SCC crack growth rate in high temperature water. 13

Fig. 11. "Repaired” microstructure after $2100^{\circ} \mathrm{F}$ for a 2-hour heat treatment. 14 


\section{ACKNOWLEDGEMENTS}

This CRADA NFE-15-05660 was conducted as a Technical Collaboration project within the Oak Ridge National Laboratory (ORNL) Manufacturing Demonstration Facility (MDF) sponsored by the US Department of Energy Advanced Manufacturing Office (CPS Agreement Number 24761).

Opportunities for MDF technical collaborations are listed in the announcement "Manufacturing Demonstration Facility Technology Collaborations for US Manufacturers in Advanced Manufacturing and Materials Technologies” posted at http://web.ornl.gov/sci/manufacturing/docs/FBO-ORNL-MDF2013-2.pdf. The goal of technical collaborations is to engage industry partners to participate in shortterm, collaborative projects within the Manufacturing Demonstration Facility (MDF) to assess applicability and of new energy efficient manufacturing technologies. Research sponsored by the U.S. Department of Energy, Office of Energy Efficiency and Renewable Energy, Advanced Manufacturing Office, under contract DE-AC05-00OR22725 with UT-Battelle, LLC. 


\begin{abstract}
This collaboration between Oak Ridge National Laboratory and General Electric Company aimed to evaluate the mechanical properties, microstructure, and porosity of the additively manufactured 316L stainless steel by ORNL's Renishaw AM250 machine for nuclear application. The program also evaluated the stress corrosion cracking and corrosion fatigue crack growth rate of the same material in high temperature water environments. Results show the properties of this material to be similar to the properties of 316L stainless steel fabricated additively with equipment from other manufacturers with slightly higher porosity. The stress corrosion crack growth rate is similar to that for wrought 316L stainless steel for an oxygenated high temperature water environment and slightly higher for a hydrogenated high temperature water environment. Optimized heat treatment of this material is expected to improve performance in high temperature water environments.
\end{abstract}

\title{
1. EVALUATION OF ADDITIVE MANUFACTURING FOR STAINLESS STEEL COMPONENTS
}

This phase 1 technical collaboration project (MDF-TC-2015-062) was begun on October 1, 2015 and was completed on September 16, 2016. The collaboration partner, General Electric Company, is a large business. Thirty (30) 316L stainless steel test specimens were additively fabricated at ORNL with the Renishaw laser powder bed system and were shipped to General Electric for characterization; properties of the specimens are comparable to those of wrought 316L stainless steel.

\subsection{BACKGROUND}

Additive Manufacturing (AM) is defined in ASTM 2792-12 as a process of joining materials to make objects from three-dimensional (3D) model data, usually layer upon layer, as opposed to subtractive manufacturing methodologies. Additive manufacturing can apply to a range of structural and functional materials and to a range of components for defense and energy applications. An advantage of additive manufacturing is that parts can be fabricated as soon as the 3D digital description of the part is created, thus establishing a new market for on demand, mass customization manufacturing. Most importantly, these processes minimize material waste and tooling requirements, as well as drastically compress the supply chain. In addition, novel components and complex structures can be produced from additive manufacturing processes at a lower cost and at a fraction of the energy required using conventional manufacturing processes such as casting, molding, and forging.

AM has significant benefit for production of stainless steel parts that are required to support General Electric's (GE) applications, especially parts likely to require a number of topology optimizations or parts containing internal features that cannot be manufactured cost effectively by traditional means. GE uses steel alloy 316L in a large number of its businesses and is considering AM components for its nuclear reactor applications. Other GE businesses use 316L (and other austenitics), and expect similar AM opportunities.

\subsection{TECHNICAL RESULTS}


This collaboration between Oak Ridge National Laboratory and General Electric Company aims to evaluate the mechanical properties, microstructure, and porosity of the additively manufactured 316L stainless steel by ORNL's Renishaw machine for nuclear application. The program also evaluates the stress corrosion cracking and corrosion fatigue crack growth rate of the same material in high temperature water environment.

\subsubsection{Materials}

Figure 1 shows the 316L stainless steel test specimens prepared at Oak Ridge National Laboratory. Tensile, Charpy, and stress corrosion cracking (SCC) specimens were built at the MDF using a Renishaw AM250 laser powder bed additive system. The specimens were heat treated and machined to the desired final geometries prior to being shipped to GE Global Research for testing. The tensile and Charpy specimens were oriented along vertical $(\mathrm{V})$, horizontal $(\mathrm{H})$, and $45^{\circ}$ angular $(\mathrm{A})$ directions relative to the building plate. A cubic block used for SCC studies was fabricated at ORNL and later was machined at GE Global Research into compact tension (CT) specimens. Two cylindrical specimens, oriented along vertical and horizontal directions, were used for porosity analysis and microstructure characterization. Tensile, Charpy, and SCC samples were solution heat treated at $1950^{\circ} \mathrm{F}$ for 1 hour, and the two cylindrical specimens were stress-relief heat treated at $1200^{\circ} \mathrm{F}$ for 2 hours.

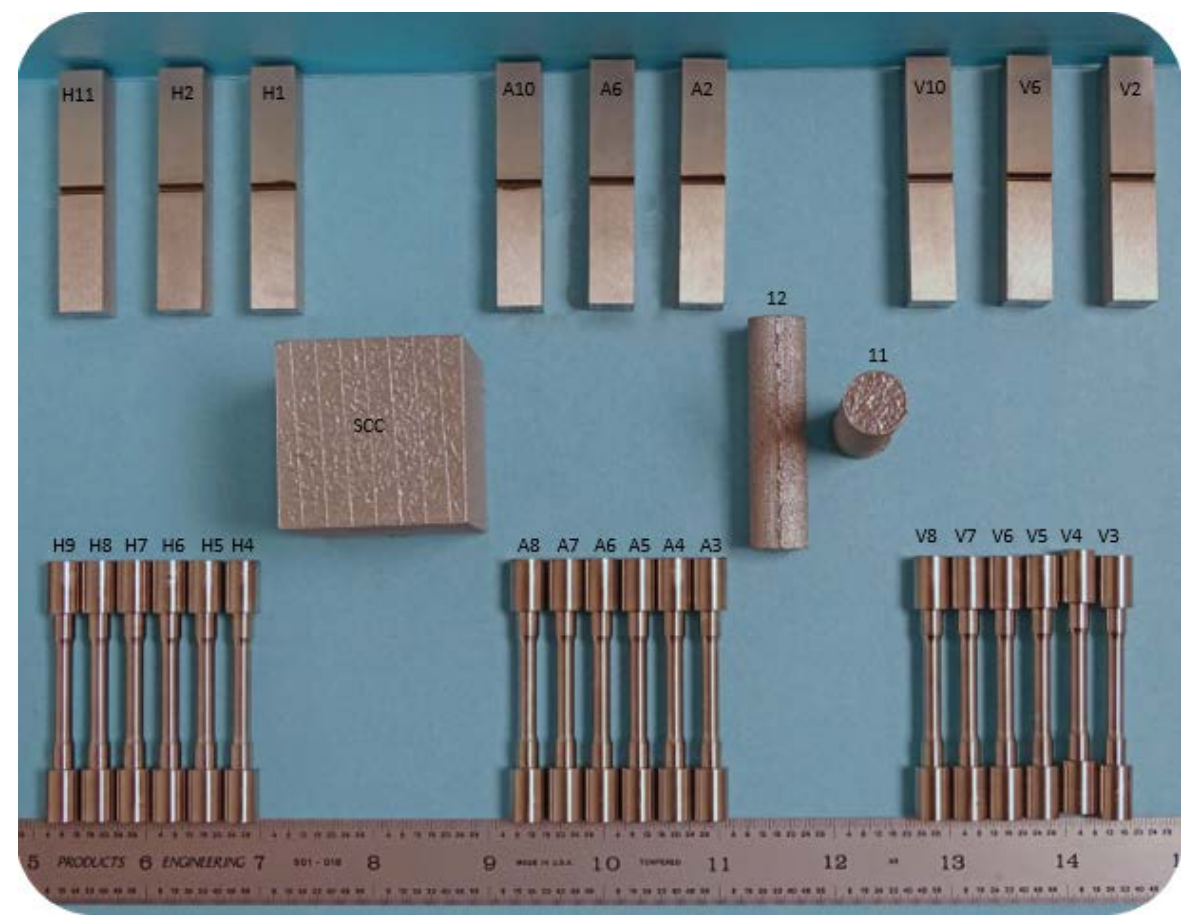

Fig. 1. Test specimens prepared at Oak Ridge National Laboratory and shipped to GE Global Research for characterization.

\subsubsection{Porosity Analysis}

Figure 2 shows the optical image of the cross-section view of the horizontal and vertical oriented specimens (stress-relieved specimens). Pores are visible in the images. Table 1 shows the porosity analysis result. In general, the as-received material shows higher porosity and larger pore size compared with other vendors' materials. The cross-section of horizontal oriented specimen shows slightly higher porosity and pore size than that of vertical oriented specimen. 


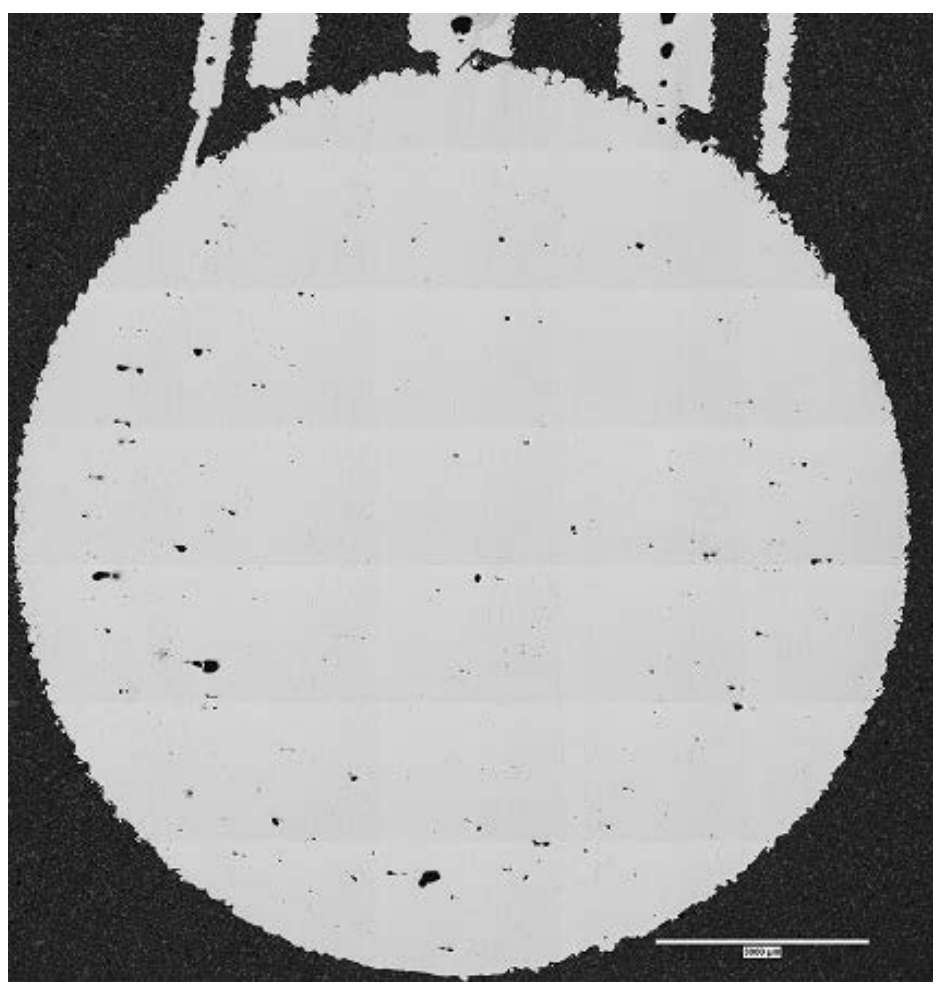

(2a) Horizontal oriented build

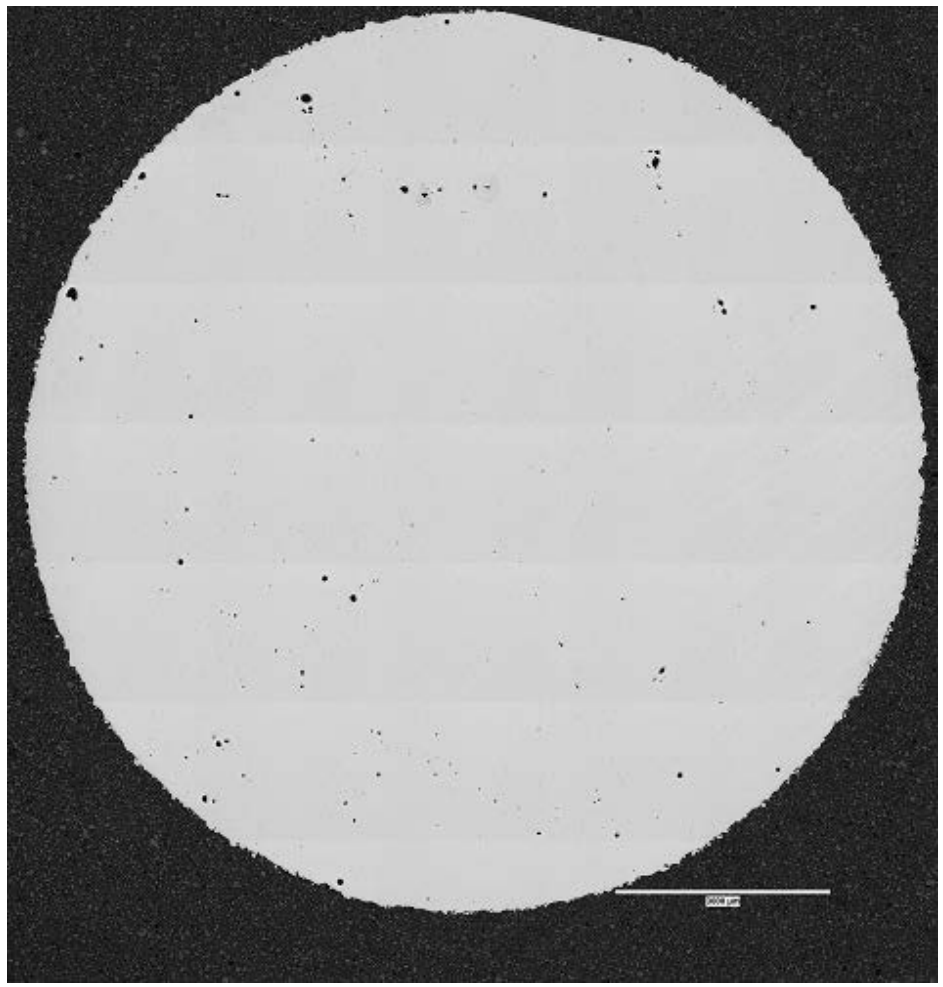

(2b) Vertical oriented build

Fig. 2. Optical view of both horizontal cross-section and vertical cross-section. 
Table 1. Porosity analysis of both horizontal and vertical cross-section

\begin{tabular}{|l|c|c|c|c|c|c|c|c|}
\hline & \multicolumn{4}{|c|}{ Porosity } & \multicolumn{2}{c|}{ Average Size } & \multicolumn{2}{c|}{$\begin{array}{c}\text { Average Spacing } \\
\text { between pores }\end{array}$} \\
\hline & Mean & $\begin{array}{c}\text { Std. } \\
\text { Dev. }\end{array}$ & Minimum & Maximum & Mean & Std. Dev. & Mean & Std. Dev. \\
\hline & $(\%)$ & $(\%)$ & $(\%)$ & $(\%)$ & $(\mu \mathrm{m})$ & $(\mu \mathrm{m})$ & $(\mu \mathrm{m})$ & $(\mu \mathrm{m})$ \\
\hline Horizontal & 0.3 & 0.5 & 0.0 & 2.8 & 16.0 & 14.5 & 1141 & 88.8 \\
\hline Vertical & 0.1 & 0.2 & 0.0 & 0.7 & 7.8 & 5.7 & 1151 & 94.5 \\
\hline
\end{tabular}

\subsubsection{Microstructure Characterization}

Figure 3 shows the microstructure of the cross-section on the horizontal oriented specimen after a thermal stress-relief treatment. The images show the area in the middle of the specimen and on the edge of the specimen. The images show a dendrite columnar structure formed inside the melt pool. Compared with other laser powder bed melted materials characterized at GE Global Research, the size of these columnar grains is towards the large side, $\sim 1 \mu \mathrm{m}$. Figure 4 shows the microstructure of the cross-section on the vertical oriented specimen after the stress-relief treatment.

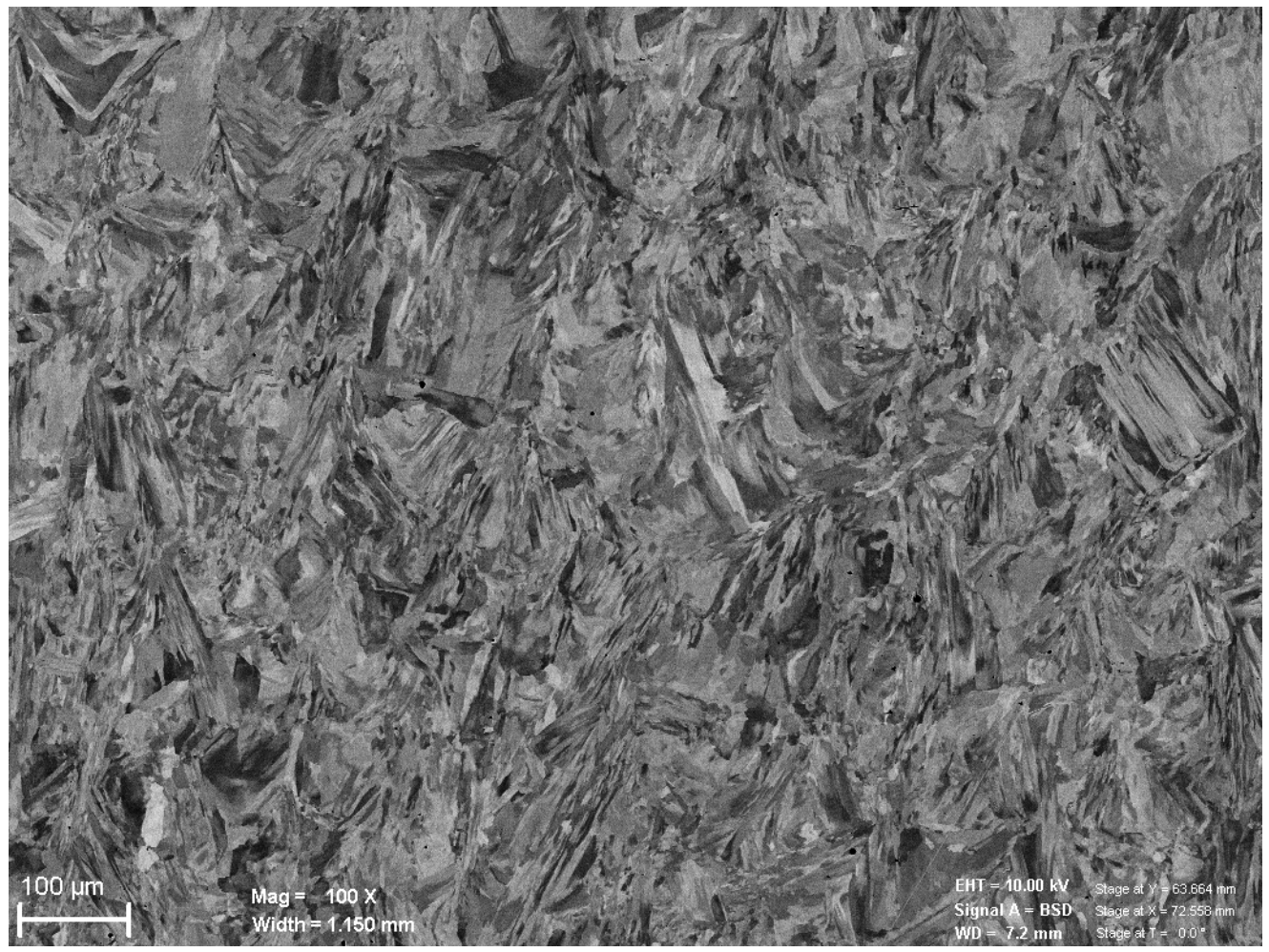

(3a) the middle of sample 


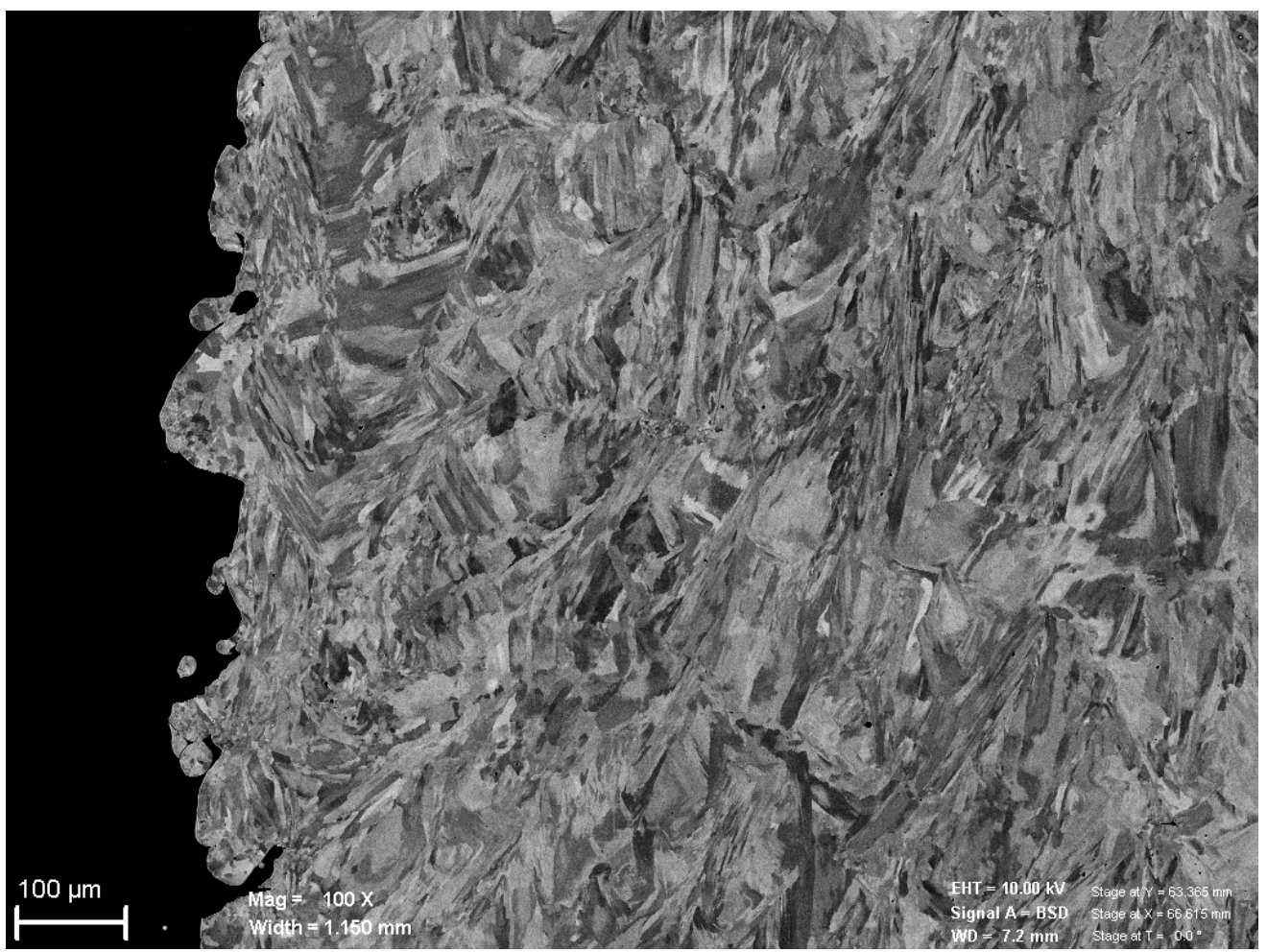

(3b) the edge of sample

Fig. 3. SEM cross-section image of the horizontal oriented specimen.

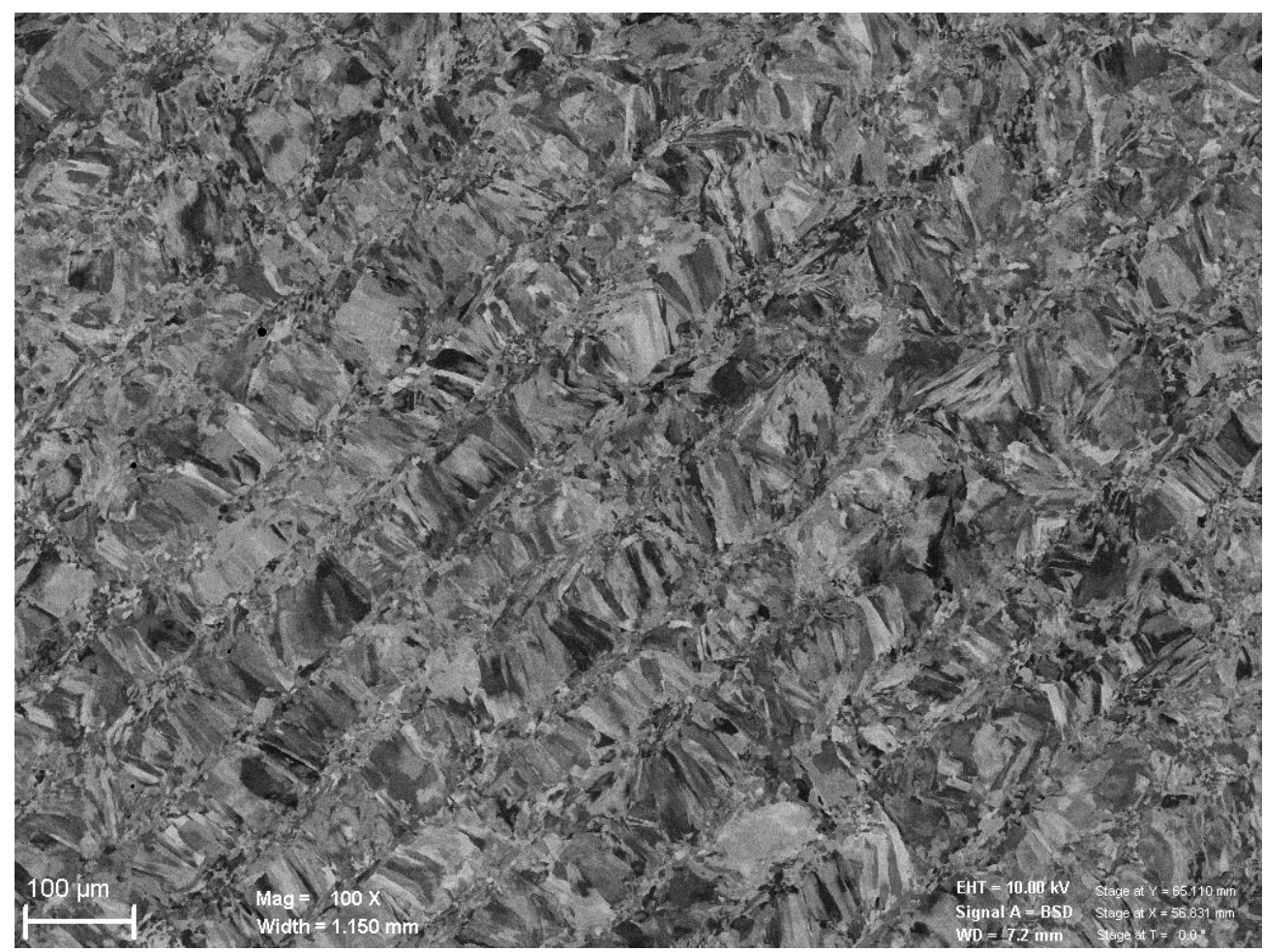

(4a) the middle of sample 


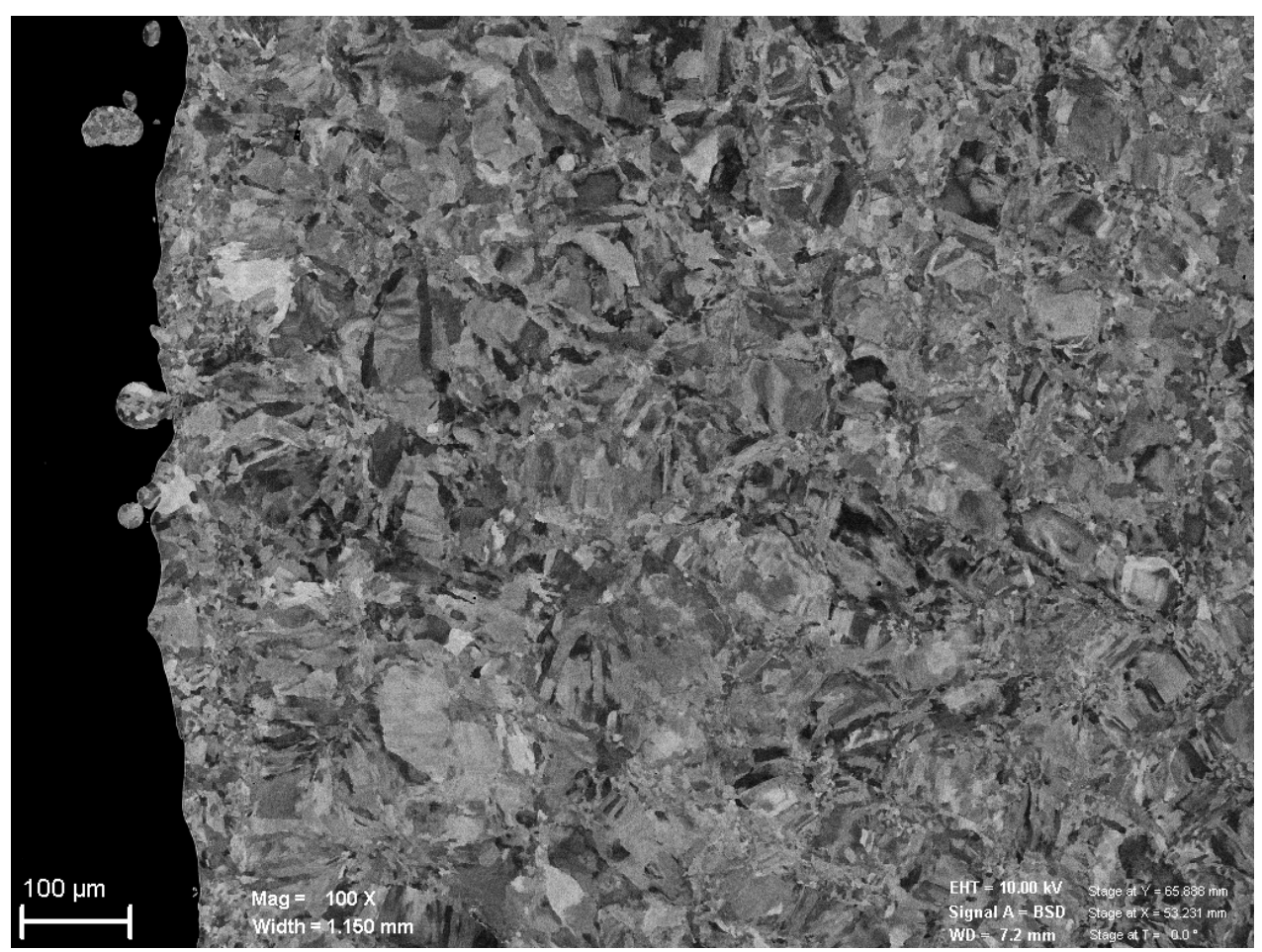

(4b) the edge of sample

Fig. 4. SEM cross-section image of the vertical oriented specimen.

\subsubsection{Tensile Properties}

Figure 5 shows the tensile properties of the solution annealed specimens tested at room temperature. With the selected annealing temperature $\left(1950^{\circ} \mathrm{F}\right)$, the material shows slightly anisotropic mechanical properties. Strengths are generally higher than the annealed wrought 316L stainless steel (YTS $\cong 42 \mathrm{ksi}$, UTS $\cong 81$ $\mathrm{ksi}$ ). Interestingly, the $45^{\circ}$ angular specimen shows the highest average yield strength which may be due to the direction of growth for the columnar structure. 


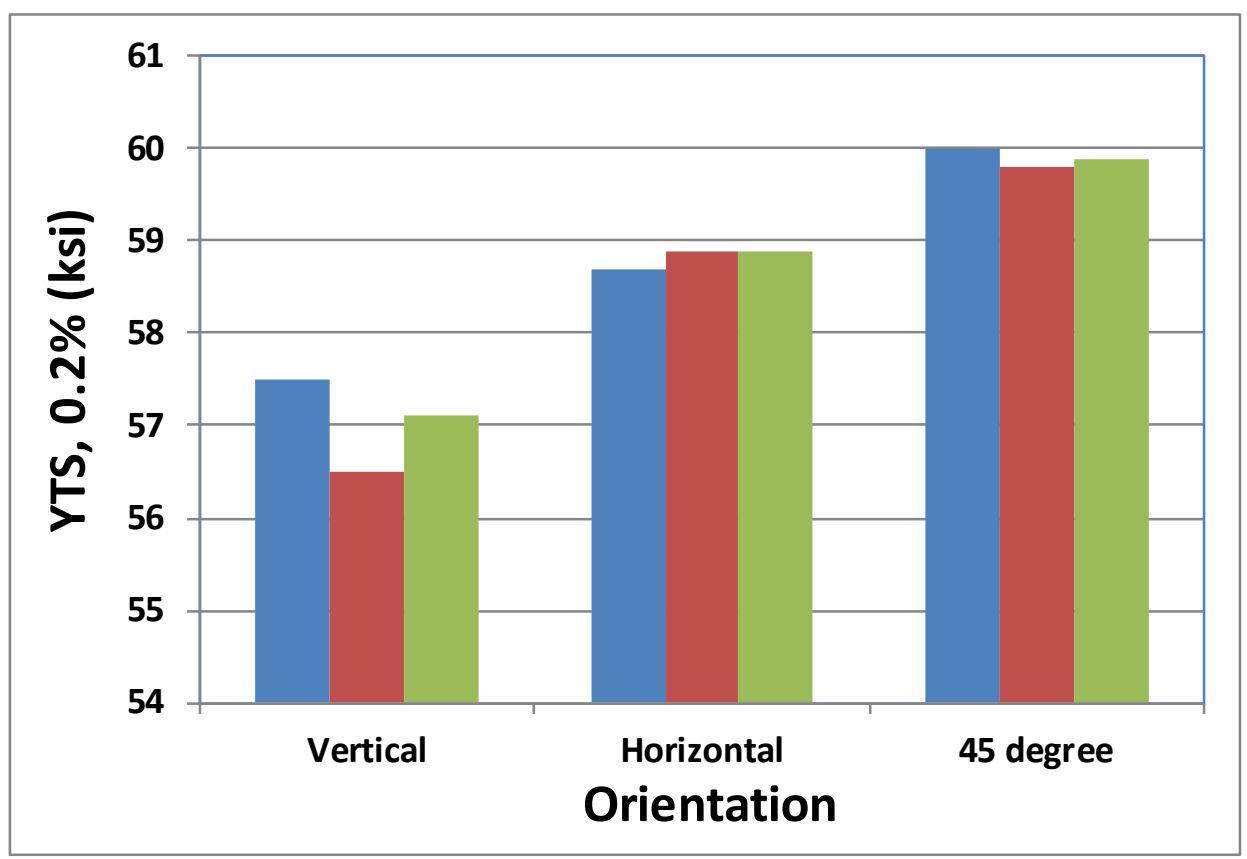

(5a) Yield strength

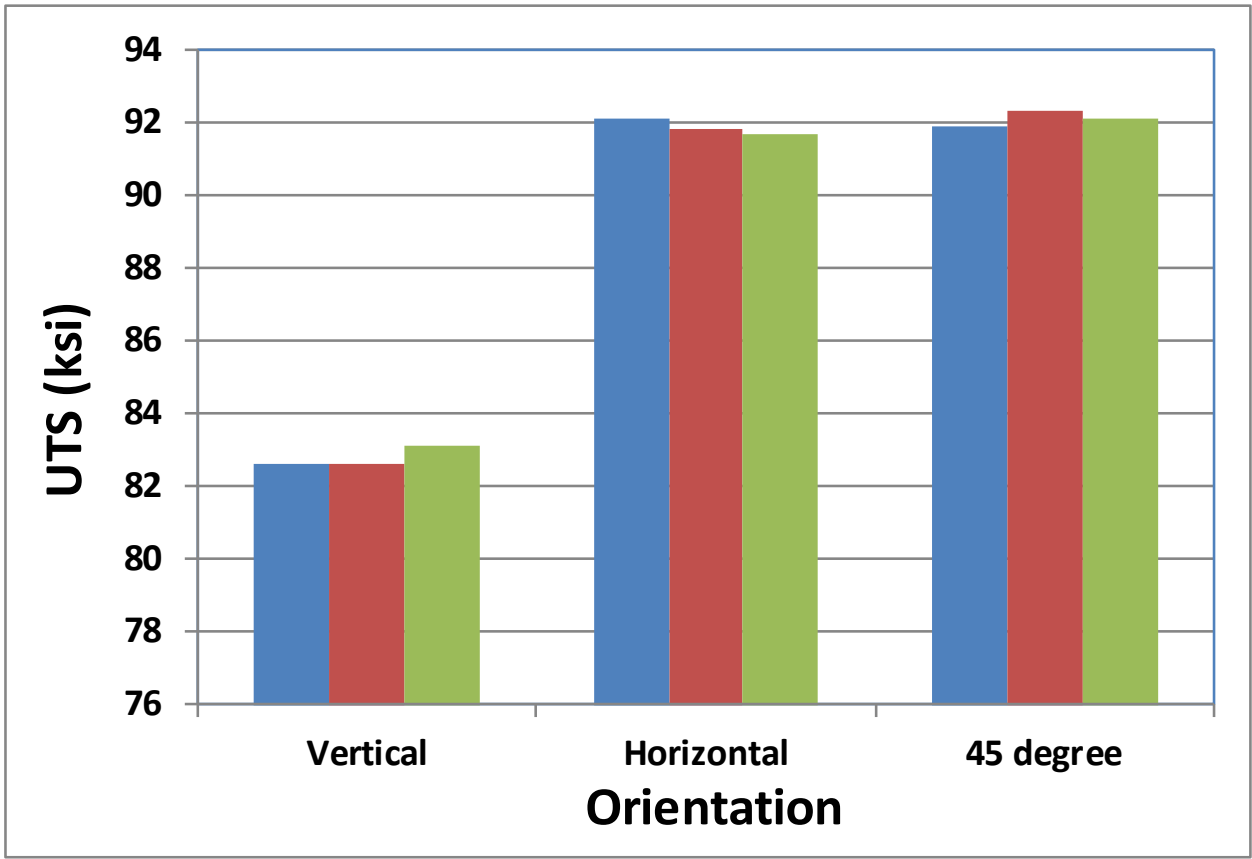

(5b) Ultimate tensile strength 


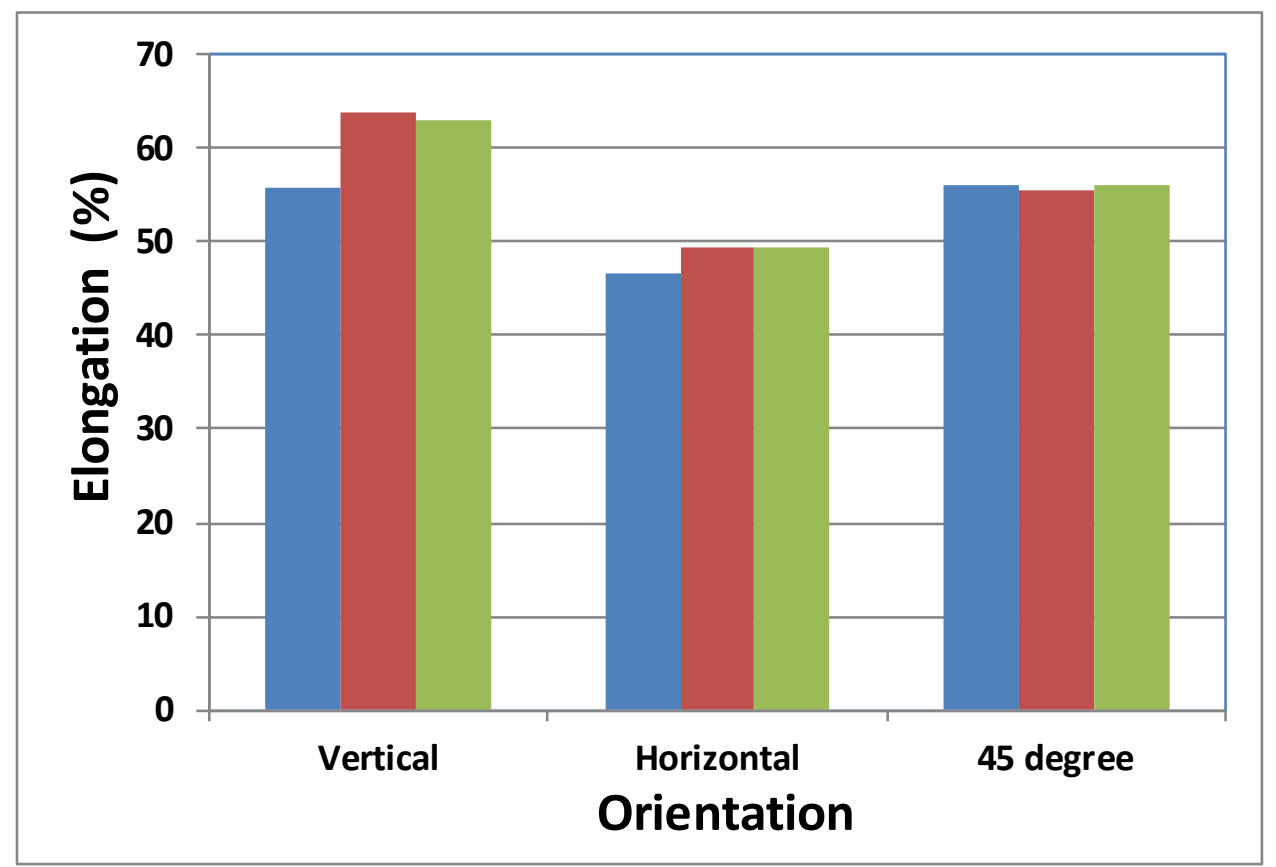

(5c) Elongation

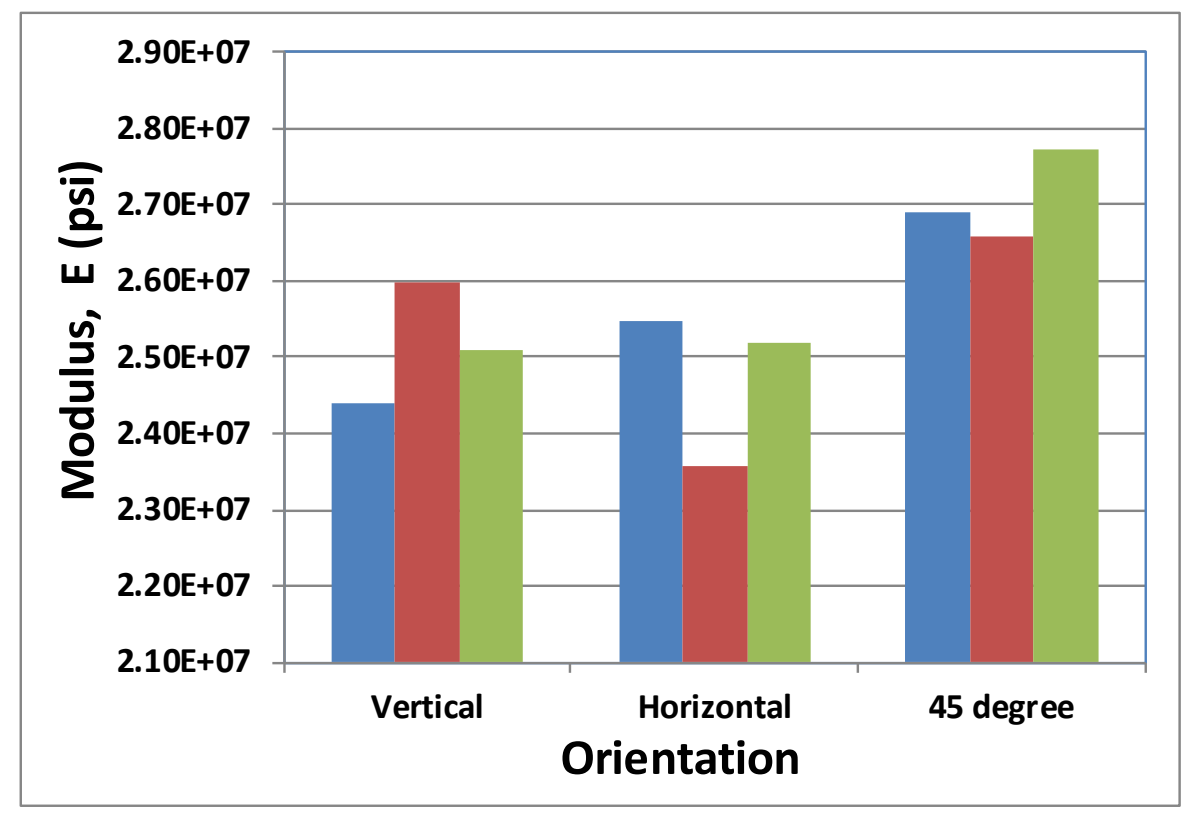

(5d) Young’s modulus

Fig. 5. Tensile properties of solution annealed AM316L SS with different orientations at room temperature.

Figure 6 shows the tensile properties of the solution annealed specimens that were tested at $288{ }^{\circ} \mathrm{C}$. With the selected annealing temperature $\left(1950^{\circ} \mathrm{F}\right)$, the material shows slightly anisotropic mechanical properties. Strengths, ductility, and Young's modulus are all lower than those measured at room temperature. Strengths are still higher than the annealed wrought materials at the same temperature (YTS $\cong 24 \mathrm{ksi}$, UTS $\cong 70 \mathrm{ksi}$ ). Interestingly again, the angular specimen shows the highest average yield strength perhaps due to the columnar structure growth direction. 


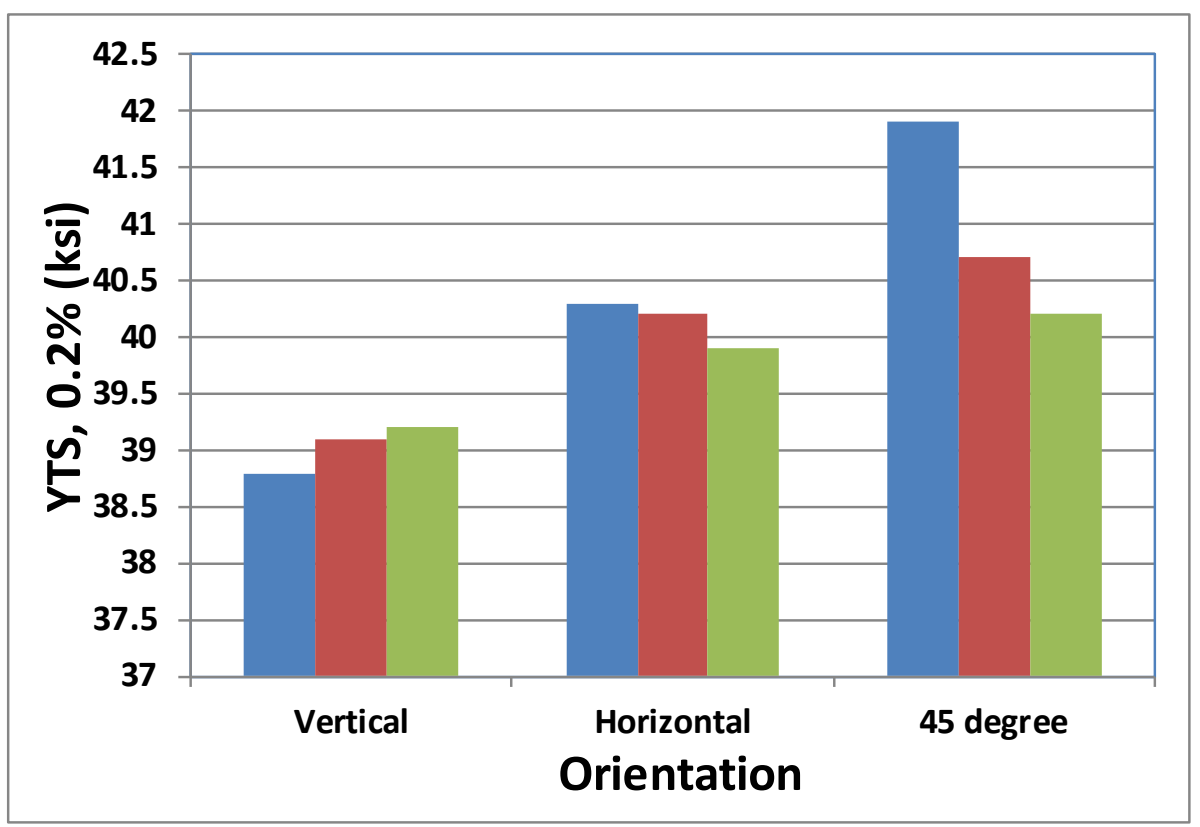

(6a) Yield strength

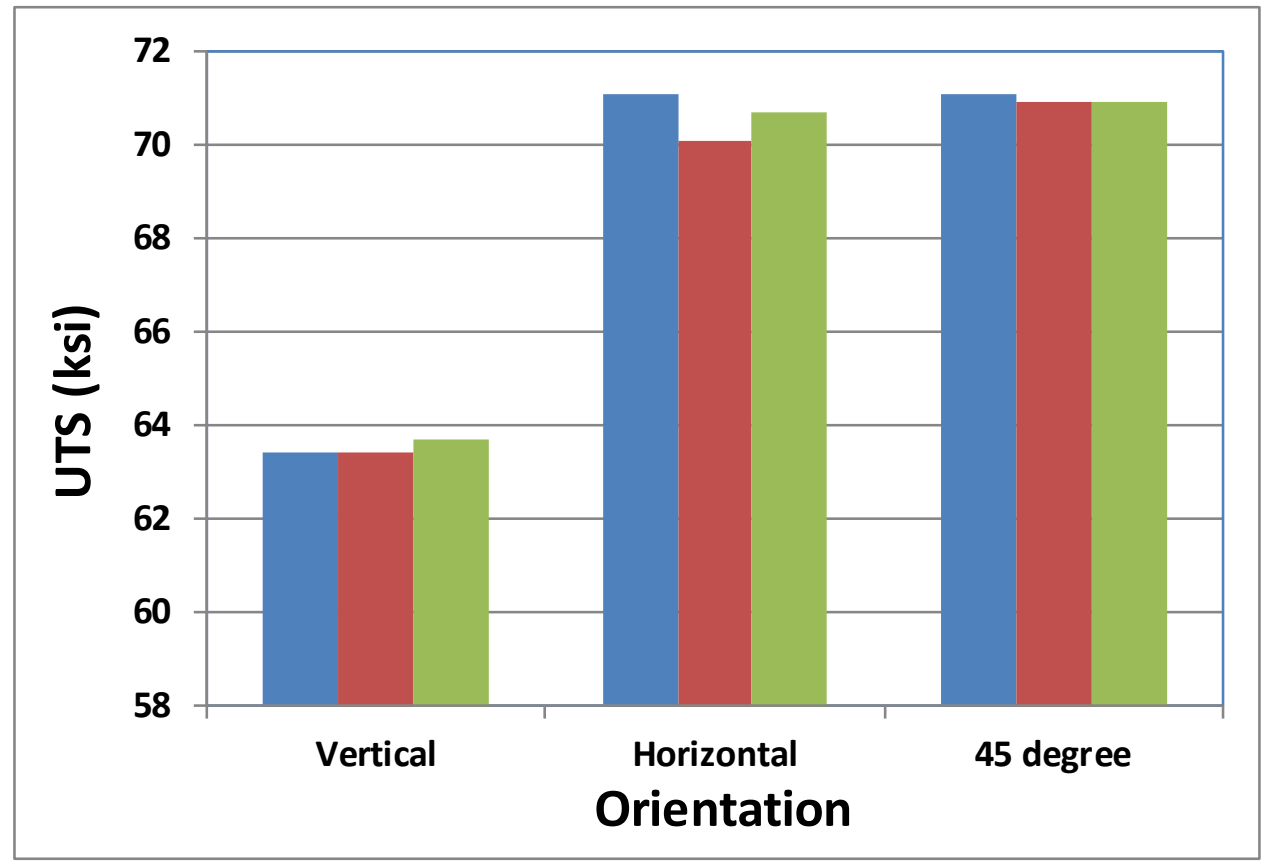

(6b) Ultimate tensile strength 


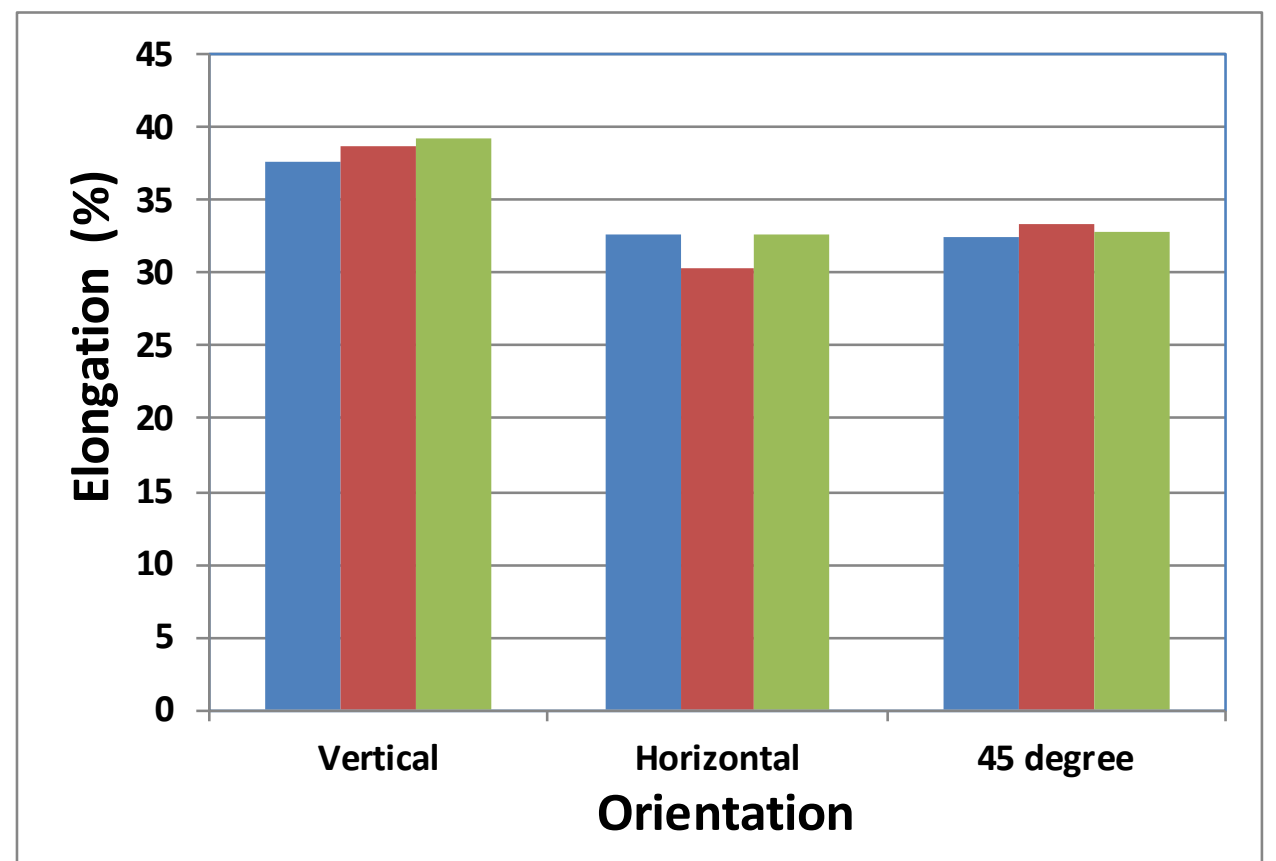

(6c) Elongation

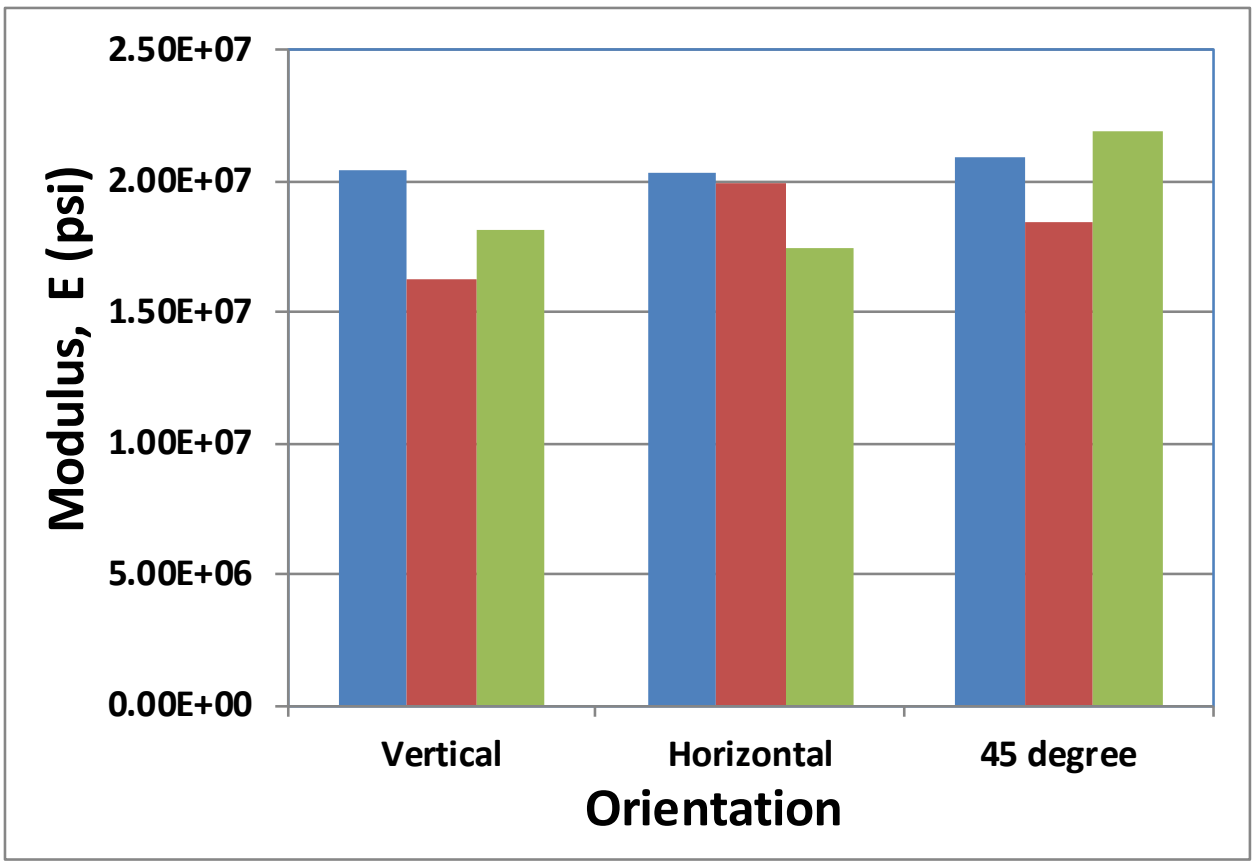

(6d) Young’s modulus

Fig. 6. Tensile properties of solution annealed AM316L SS with different orientations at $288^{\circ} \mathrm{C}$.

\subsubsection{Charpy Fracture Toughness}

Results of the Charpy fracture toughness tests are shown in Figure 7. The material shows similar toughness for different orientations. The values are in the range of 80-100 ft-lb, which is similar to wrought 316L stainless steel under solution annealing condition. 


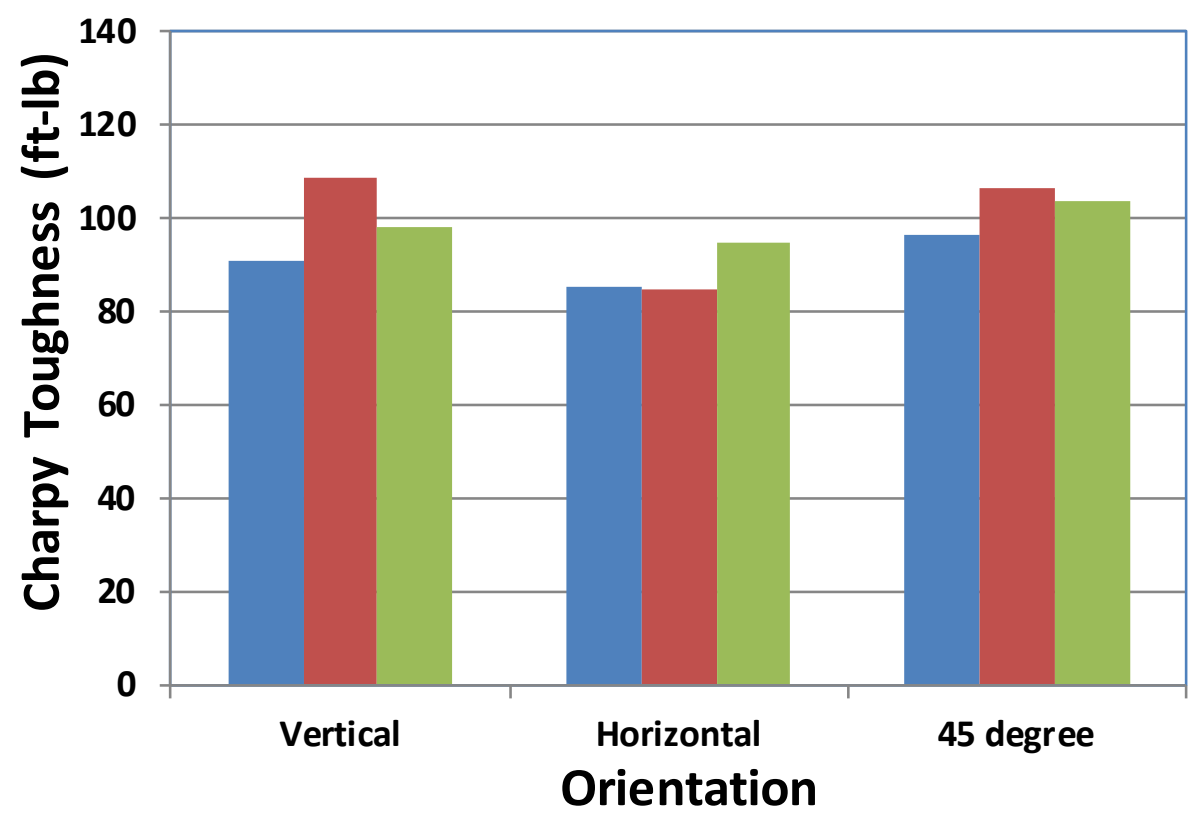

Fig. 7. Charpy toughness of solution annealed AM316L SS along different orientation.

\subsubsection{Stress Corrosion Cracking}

Stress corrosion cracking (SCC) and corrosion fatigue performances of the materials in high temperature water are key factors in materials selection for nuclear reactor applications. SCC crack growth was studied using 0.5T compact tension (CT) specimens, and in-situ crack length measurements were made using a direct current potential drop (DCPD) system. The testing environment was $288^{\circ} \mathrm{C}$ high temperature water, $2 \mathrm{ppm} \mathrm{O}_{2}$ or $63 \mathrm{ppb}_{2}$ to simulate both oxygenated and hydrogenated boiling water reactor (BWR) water chemistry. For SCC crack growth testing, the tested K level was $25 \mathrm{ksi}$ in. In parallel to SCC test, corrosion fatigue crack growth data were also generated in the high temperature water environment under various load-cycle conditions.

The orientations of the CT specimens are shown in Figure 8. The crack propagation was tested along the material buildup direction. CT specimens were instrumented with platinum current and potential leads for DCPD measurements of crack length. The specimens were electrically insulated from the loading rig by zirconia sleeves and washers. Fatigue pre-cracking was performed at the beginning of each test at $\sim 1 \mathrm{~Hz}$ and an increasing load ratio $\left(\mathrm{K}_{\min } / \mathrm{K}_{\max }\right) \mathrm{R}=0.2,0.4$, and 0.6 . Subsequent pre-crack steps to transition the crack to intergranular type were performed by decreasing the frequency to $0.001 \mathrm{~Hz}$, then by introducing a hold time, and finally to a fully constant $\mathrm{K}$ test with no cycling. The corrosion fatigue crack growth rate was obtained during pre-crack and SCC crack growth rate was obtained after the transition to constant K. A close-loop system with demineralizer was used to ensure the constant water chemistry during testing. The corrosion potentials of the CT specimen and a Pt coupon were measured relative to a zirconia membrane $\mathrm{Cu} / \mathrm{CuO}$ reference electrode.

A $20 \%$ of cold work was also introduced to the materials as our standard testing method for evaluating SCC susceptibility for stainless steel. The cold work was applied by forging material with $20 \%$ thickness reduction along the direction normal to the material buildup direction. 


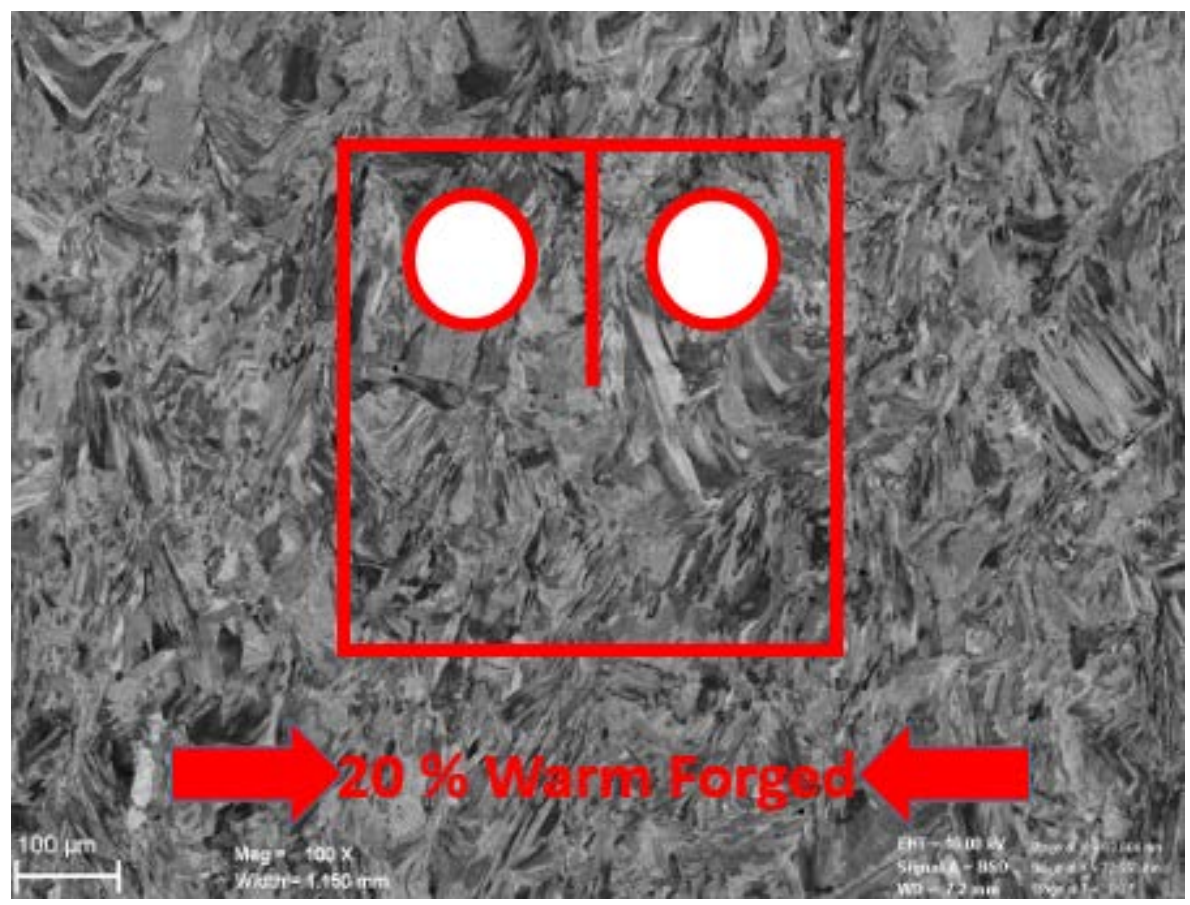

Fig. 8. The orientation of compact tension specimens in the material. A $20 \%$ warm forge was performed before machining.

Figure 9 shows the corrosion fatigue crack growth rate of the tested specimen under 25 ksi $\sqrt{ }$ in with different load cycle conditions. Figure 10 shows the SCC growth rate under $25 \mathrm{ksi}$ in. Both corrosion fatigue and SCC in oxygenated water show very similar crack growth rate in high temperature water. The material shows slightly higher SCC crack growth rate in hydrogenated water than wrought 316L material.

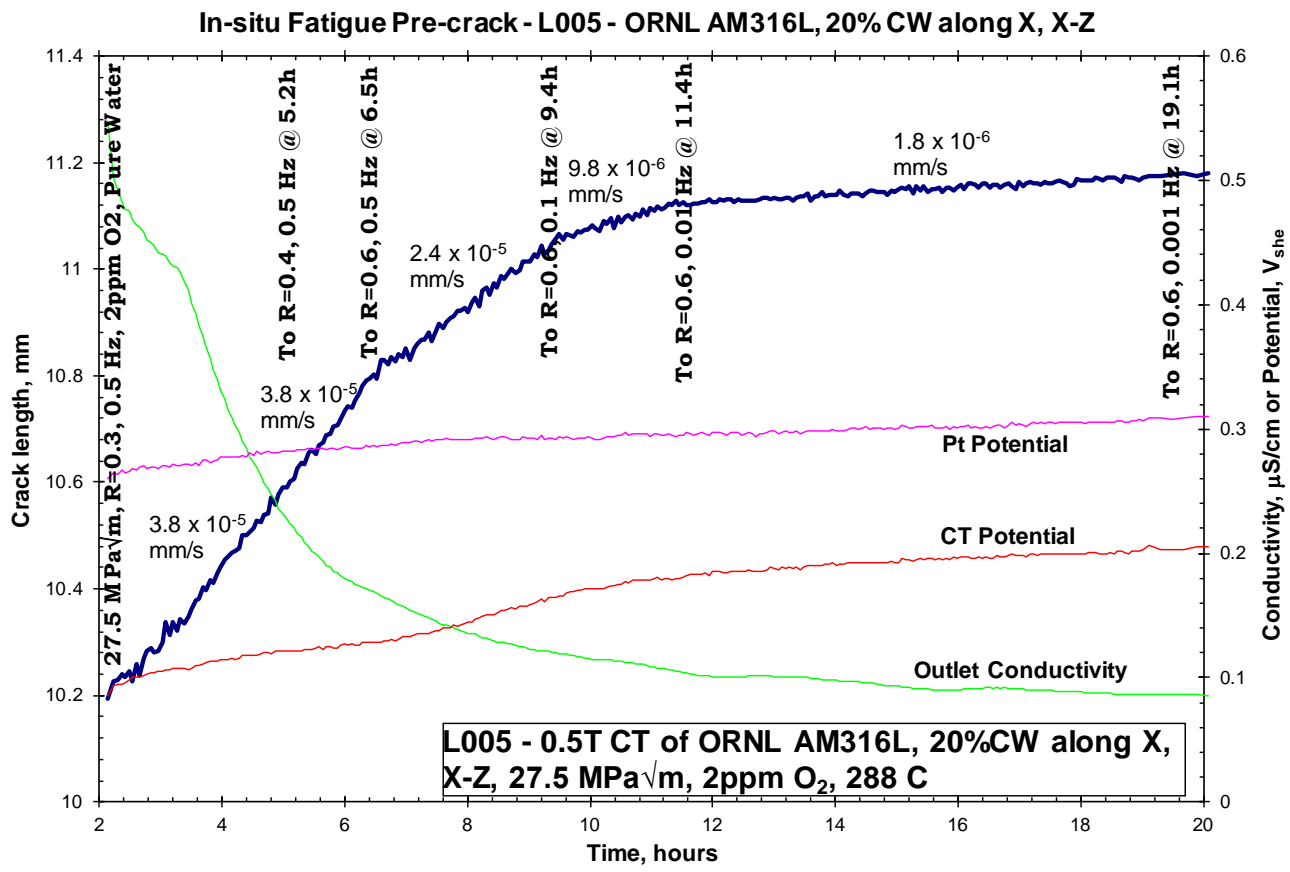

Fig. 9. Corrosion fatigue crack growth rate under different load cyclic conditions in high temperature 
water.

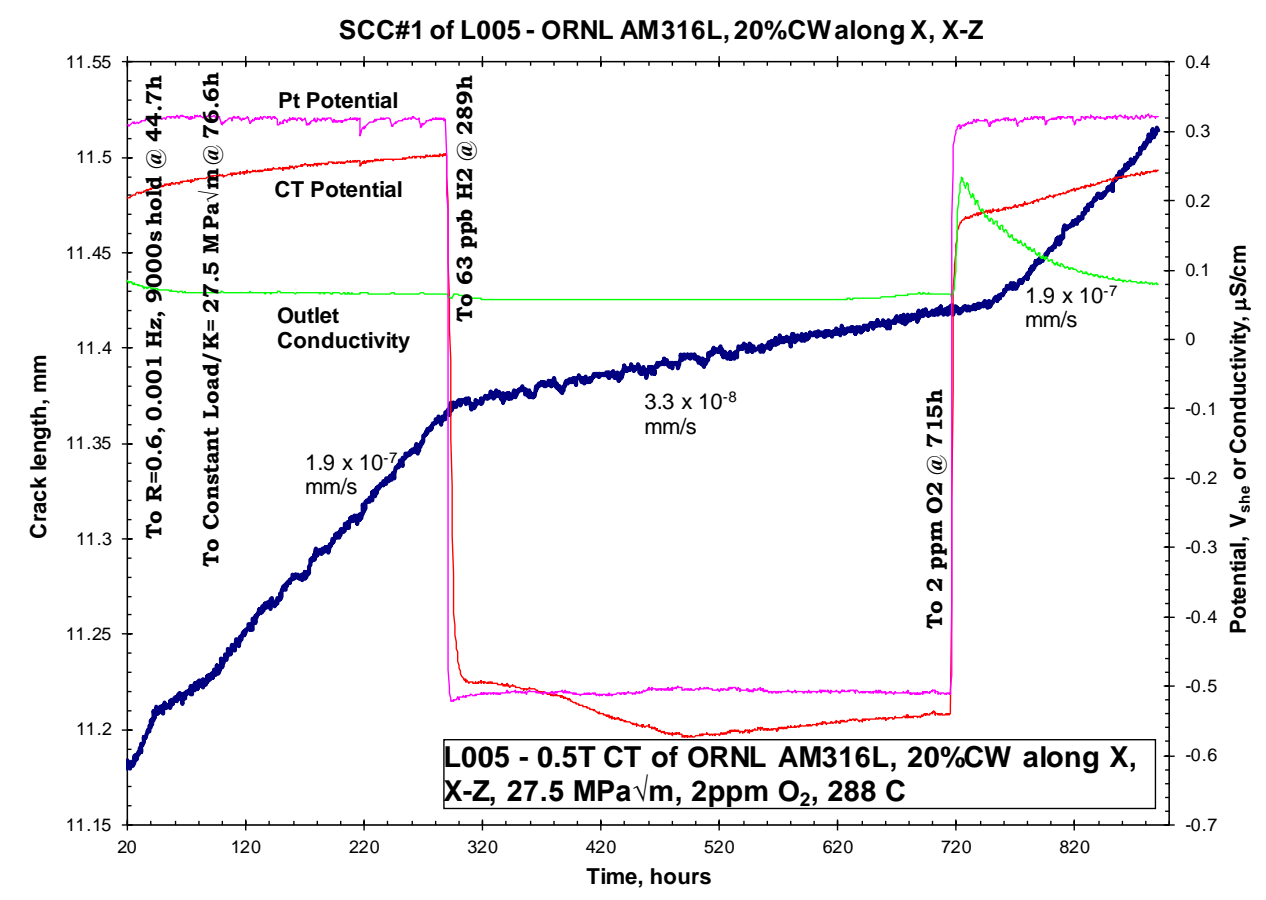

Fig. 10. SCC crack growth rate in high temperature water.

\subsubsection{Higher Temperature Annealing to Further Recrystallize the Material}

Clearly, as shown in Figure 3 and Figure 4, the solution annealing treatment at $1950^{\circ} \mathrm{F}$ for 1 hour was not enough to recrystallize the stainless steel produced using the Renishaw AM250 machine at ORNL. Researchers at GE Global Research further heat treated the same material at $2100^{\circ} \mathrm{F}$ for 2 hours to "repair" the microstructure. Shown in Figure 11 is the microstructure after the "repair" solution annealing treatment. The microstructure has been fully converted to equiaxed grain. The grain size is a little larger than expected. This confirms that this material does require higher solution annealing temperature. And further heat treatment studies are needed to optimize the grain size. 


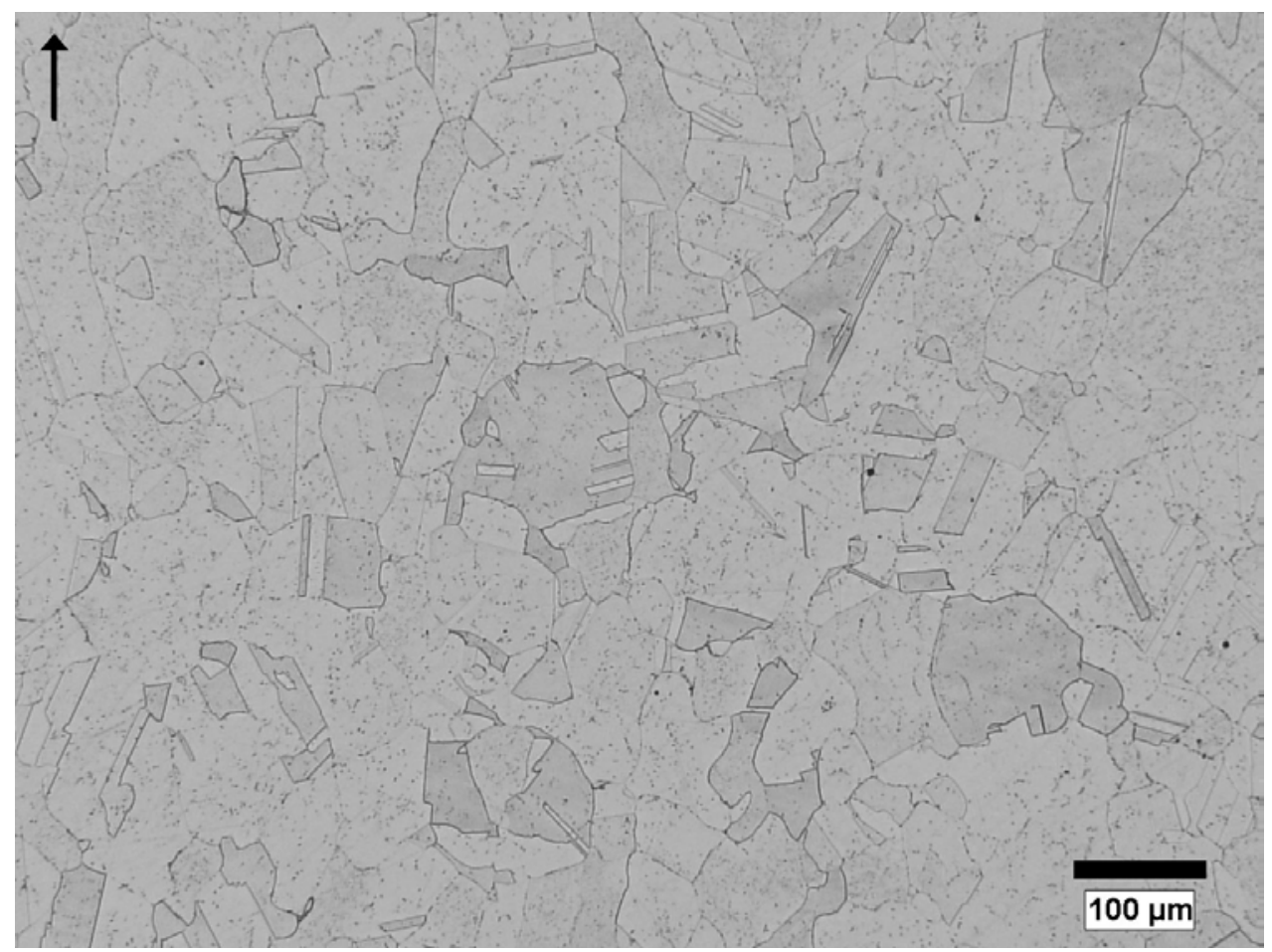

Fig. 11. "Repaired” microstructure after $2100^{\circ} \mathrm{F}$ for a 2-hour heat treatment.

\subsection{IMPACTS}

This CRADA project has successfully provided data for GE to understand the laser powder bed process based upon the Renishaw AM250 machine. The stainless steel produced by the Renishaw machine has been fully characterized for nuclear application. The results are very valuable for GE and provide a basis for comparison of performance of the Renishaw AM250 machine to that of laser powder bed equipment from other manufacturers (specifically EOS and SLM).

\subsection{CONCLUSIONS}

1) The laser scanning strategy for the Renishaw AM250 machine is intrinsically different from those for the EOS and SLM machines. The EOS and SLM machines use a line scan strategy in which scan speed is defined; this results in a continuous motion of the laser beam. For the Renishaw machine, a point scan strategy is used in which point spacing and exposure time replace scan speed; this results in a discontinuous motion of the laser beam. Because of this difference, direct translation of processing specifications from the EOS/SLM machines to the Renishaw machine is challenging.

2) The solution annealing heat treatment $\left(1950^{\circ} \mathrm{F}\right.$ for 1 hour $)$ selected for ORNL additively manufactured 316L was not high enough to recrystallize the material. Higher treatment temperatures are needed to obtain an equiaxed grain structure. Therefore, all the tested specimens used in this program were not fully recrystallized, and it is expected that testing of specimens with higher temperature treatment would lead to improved properties.

3) The as-received specimens produced by the Renishaw AM250 at ORNL were sufficient for testing at GE. The test results show slightly higher porosity and pore size than specimens produced from other laser powder bed systems.

4) Mechanical properties of as-received ORNL additively manufactured 316L stainless steel specimens meet requirements for nuclear reactor applications. 
5) Stress corrosion crack growth tests on as-received ORNL additively manufactured 316L show reasonable crack propagation rate in oxygenated high temperature water, which is similar to wrought material. The crack growth rate is slightly higher than wrought in hydrogen water chemistry, which is probably due to the un-recrystallized grain structure. We expect an optimized heat treatment would reduce the crack growth rate for both the oxygenated and hydrogenated chemistries.

\section{PARTNER BACKGROUND}

General Electric Company is the world leader of advanced manufacturing in energy, aviation, and oil \& gas. The company is committed to deploy additive manufacturing to reduce fabrication cost, energy consumption and material waste, and improve production efficiency. GE's Corporate R\&D division, GE Global Research, has rich expertise and experience in advanced material and manufacturing development and nuclear material evaluations. GE's Power \& Water business is an international leader in energy products and services, serving power generation, industrial, marine, oil and gas, and distributed generation markets. It is the industry leader in heavy-duty gas turbines with over 5,000 gas turbines installed worldwide. GE's F-class gas turbine fleet has nearly 30 million hours of operating experience. GE-Hitachi Nuclear Energy, a joint venture between GE and Hitachi, is a major nuclear technology and service provider. 